\title{
VALIDATING PURCHASE INTENTIONS FOR GREEN COSMETIC PRODUCTS: APPLYING AND EXTENDINTHEORY OF PLANNED BEHAVIOR
}

\author{
Shradha Chhetri ${ }^{1 *}$, Dr. Semila Fernandes ${ }^{2}$, Prof. Saina Baby ${ }^{3}$ \\ 1,2,3 Symbiosis Institute of Business Management (SIBM), Electronics City, Hosur Road, Bengaluru, Karnataka, India. \\ Symbiosis International (Deemed University) (SIU), Pune.
}

\begin{abstract}
In the last few years, consumers in the Asian market have become conscious of green products and their impact on environmental welfare. Millennial consumers specifically, have started preferring environment friendly, socially responsible products and have come to be known as quick spenders tending the hedonistic consumption. The key intention of this research is to ascertain the variables that have an impact on the purchasing intentions which thereby affects the willingness of millennial buyers to pay a premium for eco-friendly and organic cosmetics in India by expanding the Theory of Planned Behavior by providing a structural equation model (SEM) and path analysis. Results of the study show that the subjective norms are an essential element affecting the environmental concerns and the attitudes of individuals towards green cosmetics which in turn, influence customers intention of purchasing these products and their willingness in paying a premium The research concludes that, with the presence of subjective norms to impose environment-friendly behavior and the correct attitude of individuals towards green cosmetics, the purchase intention and willingness of the millennial buyers to pay a premium for eco-friendly cosmetic products high.
\end{abstract}

Keyword: Theory of Planned Behavior, environmental concern, subjective norms, attitude of individuals, purchase intention, willingness to pay a premium

\section{Introduction}

Rates of consumption have risen significantly in the last few years. This has led to environmental concerns viz. generation of waste, atmospheric pollution, and contamination of land. (Paettie, 2001; Song, et al., 2017). These issues have created awareness among a group consumer about the necessity to change the usual consumption patterns to promote environmental sustainability. (Smith, Stirling, \& Berkhout, 2005; Pickett-Baker \& Ozaki, 2008). These changes have made marketers research on this new domain of green consumer behavior. It is imperative to explore green consumer behavior because the consumers align their environmental consciousness with activities of firms related to sustainable environmental practices. (Barber \& C Taylor, 2009; Khare,
2015). A variety of studies on this topic have been carried out by developed countries such as in the Hong Kong (Lai \& Cheng, 2016), United Kingdom (Charter, Peattie, Ottman, \& Polonsky, 2002), and America (Diaz \& Ashton, 2011; Ottoman, 1998). However, studies conducted he developing countries like India are very limited (Yadav \& Pathak, 2016). India is home to the second-largest population across the globe and the Indian economy stands third in the world in terms of (PPP) purchasing power parity. Millennials occupy a considerable proportion of the total population accounting for $34 \%$. Consciousness among the millennials about the advantages of environmentally safe items is high. (Jaiswal \& Kant, 2018). Higher educational and awareness levels compared to the earlier generations is responsible for higher environmental consciousness among the millennials (Prakash \& Pathak, 2017). Raising levels of environmental consciousness among the consumers has motivated companies to change their perspectives on green products. (Prothero, 1990). This change is visible in the market through enhanced availability of organic and non-toxic products, especially in the cosmetic industry. The cosmetic industry in India exhibits stable growth prospects with a CAGR of $7.6 \%$ during the period 2020-23. This industry has revenue clocked in US\$ 6029 Million in 2020 (Statista).

The opportunities of the growing cosmetic industry and the changing behaviors of Indian millennials towards green products have made it a lucrative market with little research available on the topic. This paper aims to look into how environmental concerns shape the attitudes of millennials and to demine the relationship between attitudes of individuals, intention to purchase, and their willingness to pay a premium for environmentally friendly cosmetics.

\subsection{Objectives:}

(1) To probe the elements which impact the green purchase behavior of the millennial Indian consumers for cosmetic products

(2) To identify the impact of subjective norms and environmental concerns on attitudes of millennial consumers, which influences the green purchase intentions and the willingness of buyers to pay a premium 


\subsection{Theoretical Background}

Purchase intention is skinned from the theory of planned behavior which depicts how certain behavior and characteristics lead to a tenacity to purchase something. The theory is built on the notion that most human behavior is an outcome of a person's attempt to accomplish a particular intention to conduct a particular behavior and their capacity to settle on a cognizant choice about it. (Ham, Jeger, \& Ivković, 2015). This theory is mainly used to understand the key elements of deliberate human behavior It has received support in numerous research papers commissioned by several research agencies and scientists (Ajzen, 2001; Eagly \& Chaiken, 1993; Ajzen, 2011).

Personal attitude is defined as a withstanding neural and mental frame of mind as a result of the experience which affects a person's reaction to certain conditions and objects he interacts with(Allport, 1935). According to Ajzen (2011), an individual is required to follow a certain kind of behavior if he has an absolute, definitive, and decisive attitude toward undertaking the behaviors. Subjective norms allude to the convictions that a notable individual or gathering of individuals will favor and support. They reflect one's apparent social strain which has an explicit role and is positively influenced by society. Subjective norms greatly influence behavioral intentions, majorly in the context of behaviors associated with beauty and skincare management (Hillhouse et al., 2000). Additionally, there has been a close correlation between purchase intentions and subjective norms with regards to green consumer behavior research (Kalafatis et al., 1999; Bamberg, 2003). Subjective norms are further be divided into descriptive and social norms. Descriptive norms are the genuine activities and practices others are following, whereas, social norms allude to the impression of others' suppositions on how one ought to behave (Ham, Jeger, \& Ivković, 2015). Perceived behavioral control involves the view of one's capacities and feeling of authority over a circumstance and is characterized as an amalgamation of locus of control, for example, conviction about the measure of control that an individual has on occasions throughout his existence and selfadequacy i.e. perceived ability in performing a task (Ajzen,2002).

The theory of planned has exhibited greatness in giving a system to conceptualizing, estimating, and recognizing factors that administer behavior and behavioral intention (Montaño, 2015). Various degrees of situational and individual components can affect how much attitudes are prescient of or converted into a behavioral intention (Iris \& Wim, 2008).

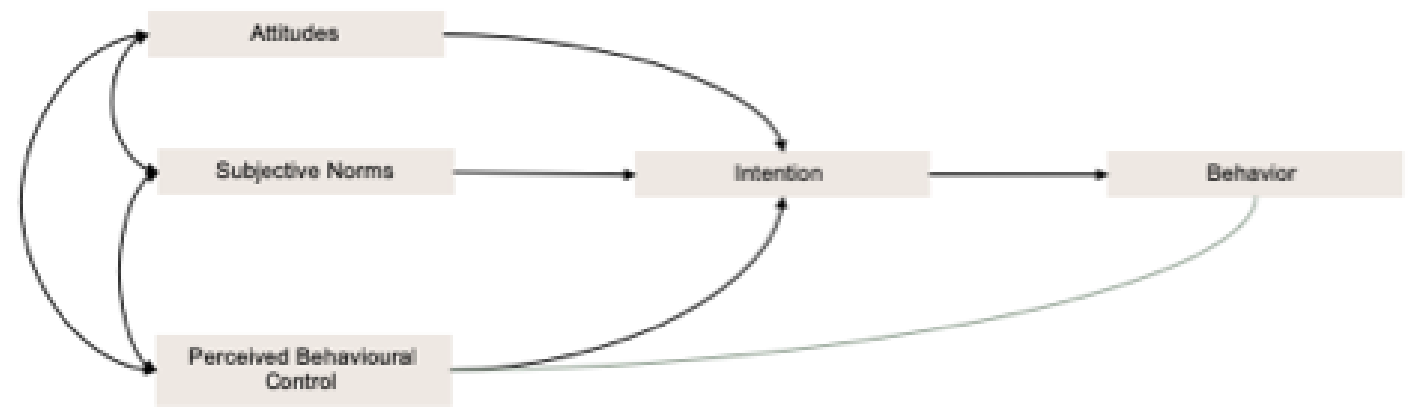

Figure 1: The Theory of Planned Behaviour

\section{$2 \quad$ Literature Review}

The Theory of Planned Behaviour is adopted for assessing the purchase intentions of various products (Pelling \& White, 2009; Kaiser, Wölfing, \& Fuhrer, 1999; Ajzen, 2011). This framework has also been used to study purchase intentions with specific reference to the environmental aspects of purchase behavior consisting of the nexus between the selfidentity of the consumer and the consumption behavior (Sparks \& Shepherd, 1992) Consumers' willingness to pay a premium while engaged in green purchasing has also been explored by few empirical studies. (Chekima, et al., 2015). Lately, consumers in the Asian market have become more aware of green products and their impact on environmental welfare (Farzana, Azila, \& Mohammad, 2020). Millennial consumers specifically, have started preferring environment friendly, socially responsible products and have come to be known as quick spenders tending the hedonistic consumption (López-Fernández, 2020). Consumer incredulity of corporate environmental activities is constantly increasing (Constantinos \& Dionysis, 2017) and demand a healthful style of living and clean label items. This has brought about the development of eco-accommodating items in the health and beauty markets (Banerjee, 2017) (Basu, Thomas, \& Acharya, 2007). This expansion in demand for natural organic beauty products and cosmetics has made organizations utilizing green raw materials that are not synthetic. (Lee, Lusk, Mirosa, \& Oey, 2014). The purchaser's view of health and beauty adds to their buy choices and impacts their consumption habits (Jang \& Bonn, 2011). This research aims at studying the factors affecting buying intentions and willingness of buyers to pay a premium for eco-friendly and organic cosmetics across the Indian market. 
2.1 Sknowledge (Kaur, Duggal, \& Suri, 2019). Evidence from

ubjective Norm Conformity concerning issues related to environment protection

Subjective norms deal with the anticipated pressure on people to conform with a certain set of behaviors. (Ajzen, The Theory of Planned Behavior, 1991). Human beings tend to derive reasoning from observed behaviors existing in society (Gilbert \& Malone, 1995). The collectivist societal nature existing in India (Verma \& Triandis, 1999; Khare, 2011) makes subjective standards and obligations a priory of individuals (Wheeler, Reis, \& Bond, 1989; Gorodnichenko \& Roland, 2012). The existence of higher-level environmental consciousness in society encourages individuals to drive their purchase intentions towards green products.

\subsection{Perceived Concerns of the Consumers about Environmental Issues}

Perceived environmental concern deals with the degree to which a consumer believes that their activity has an impact on dealing with an issue (Ellen, Wienner, \& Walgren, 1991; Majláth, 2010). Consumers' purchase intention to a larger extent is susceptible to Environmental concerns (Dunlap \& Van Liere, 1978; Hartmann \& Apaolaza-Ibáñez, 2012). Consumers have a positive attitude towards the brands that reflect their perspectives on environmental issues. Due to the concern about environmental issues, consumers try to purchase products having a marginal effect on the environment (Gadenne, Sharma, Kerr, \& Smith, 2011). A positive attitude towards green goods is evident in consumers having high environmental concerns (Jaiswal \& Kant, 2018).

\subsection{The attitude of consumers regarding Green \\ Products}

Consumers' behavior towards shopping can be understood as a low-cost theory and researchers have found that with a little inconvenience, green consumerism can be made viable (Moser, 2016). Environmentally responsible behavior can be stimulated in consumers due to the influence of various factors. (Thøgersen, 2009). The study of these factors motivating consumers to be environmentally responsible provides insights about green purchase intentions. (Diekmann $\&$ Preisendörfer, 2003). According to an India based research, $86 \%$ of consumers exhibited a positive attitude regarding the use of energy-saving products, and $79 \%$ concerning green packaging (Jaiswal \& Kant, 2018).

\subsection{Intention towards Green purchase behavior}

The purchase behaviors of the consumers' conduct towards eco-sustainable goods are defined as Green purchase intention (Chan, 2001). The intention towards green purchase behavior arises out of a consumer's interaction with the social environment. This social environment consisting of family, friends, and even social media helps consumers to gain existing literature identifies a lack of information as the reason for consumers not able to find green products (Brown \& Wahlers, 1998). However, the acquisition of knowledge about environmentally friendly products may motivate consumers to develop a green purchase intention.

The purchase intention of a consumer towards a green product is usually reflected in the conscious transformation of consumer's belief into a purchase decision and also consumer's willingness towards product purchase (Joshi \& Rahman, 2015). A stronger intention to carry out a particular behavior translating to a higher chance of the action taking place is well documented in the Theory of Reasoned Action framework (Ajzen, 1991).

\subsection{Green Products - Willingness to pay a premium}

The monetary cost of a commodity plays an integral part in the purchase decision cycle for customers, the purchase intention. The willingness to pay a premium for eco-friendly commodities is perceived as an environmentally sustainable behavior. Lack of familiarity with the manufacturer reduce the probability of consumer buying a product (Glegg, Richards, Heard, \& Dawson, 2005) and it also reduces the chances of the consumer paying a premium. The organizations must understand and target their products at the customer segments which are able and willing to pay a premium for green goods (Gleim, Smith, Andrews, \& Cronin, 2012).

Empirical research linking the subjective norms, behaviors, and motivations with green purchase intentions is seldom available in the Indian context. This unique research aims at understanding the purchase intentions towards green products and the inclination of Indian consumers to pay a higher price with specific reference to the cosmetic industry. This study attempts to extend the well-theorized framework of planned behavior (Ajzen, 1991). This study also proposes a modified framework by incorporating social norms, purchase intention, environmental concerns, attitudes, and the willingness to pay of millennial Indian buyers for Green products.

\subsection{Hypothesis}

Through environmental behavioral science, environmental concerns are viewed as a person's responsibility (Hines et al.,1987). Ecological apprehension is one of the cognitive measures to foresee the impact of social norms on the attitudes of individuals (Kant \& Jaiswal,2018). Soyez, 2012 in her research studies individual pro-environmental values and concludes that environmental apathy and subjective norms have a positive relationship. This literature can be used to form the following hypothesis: 
H1: premium for green goods is perceived as an environmentally

Subjective norms that represent ethical motives favorably influence environmental concerns of Indian millennials towards purchase intention of green cosmetic products

Chang (1998) investigated the association of attitudes of individuals and subjective norms and thereby to analyze how positive attitudes towards products influence the purchase intention for the products (Chang, 1998). The impact of an individual's attitude towards green purchase intentions has also been analyzed by Jaiswal \& Kant, 2018. This is consistent with the Theory of Planned Behaviour (Ajzen, 2011) and several research scholars including Huque et.al. 2014; Yadav and Pathak, 2016. These researches are used to form the following hypothesis:

H2: Subjective norms represented by ethical motives have a confirming effect on the attitude of millennial Indian buyers concerning the purchase intention of green cosmetic products

H4: Consumer's favorable attitude regarding environmental protection has a considerable influence on the green purchase intention of millenarian Indian consumers towards cosmetic products

Empirical studies have identified a strong and clear nexus between environmental issues and green purchase intention (Jaiswal \& Kant, 2018). The studies additionally state that there is strong evidence that shows that environmental concern impacts the attitudes of individuals towards green products. Soyez, 2012 states that there is a strong association between environmental apathy and attitudes. Scholars concluded that environmental concerns have an immediate and significant effect on the mindset and attitudes of individuals towards green products (Mostafa, 2007). Environmental concerns may also have an impact on consumers' buyers' intentions for green cosmetics (Yadav and Pathak, 2016). The belief is that customers with strong and excessive environmental concerns are closely correlated with their optimistic attitude and outlooks toward green goods which in effect contributes to a high degree of purchasing intention for these items.

H3: Concerns of Millennial consumers about Environmental issues have a positive impact on their attitude concerning the purchase intention of green cosmetics

H5: Concerns of Millennial consumers about Environmental issues develop a positive influence on their purchase intention of green cosmetics

Healthy and safe products that are sustainable and eco-friendly are desired by consumers regardless of being priced more than the others (Zhang, et al., 2018). The willingness to pay a sustainable behavior. Lack of familiarity with the manufacturer reduce the probability of consumer buying a product (Glegg, Richards, Heard, \& Dawson, 2005) and it also reduces the chances of the consumer paying a premium. The attitudes of individuals play a huge role in determining whether they exhibit a pro-environmental behavior while making a purchase. Xu, et al., 2012; Yadav \& Pathak, 2017 and Wei, Ang, \& Jancenelle, 2018, in their research conclude that the purchase intention of green cosmetic products positively affects the disposition a to pay premium. Chaudhary \& Bisai, 2018 have explored the role of consumer attitudes as a moderator between purchase intention and green purchase behavior.

H6: Consumer's attitudes positively affect the willingness to pay a premium for green cosmetics for millennials in India.

H7: The willingness of millennial buyers to pay a premium for green cosmetics is positively connected with their Purchase intention

This is elucidated with the support of figure 2 constructed by the author

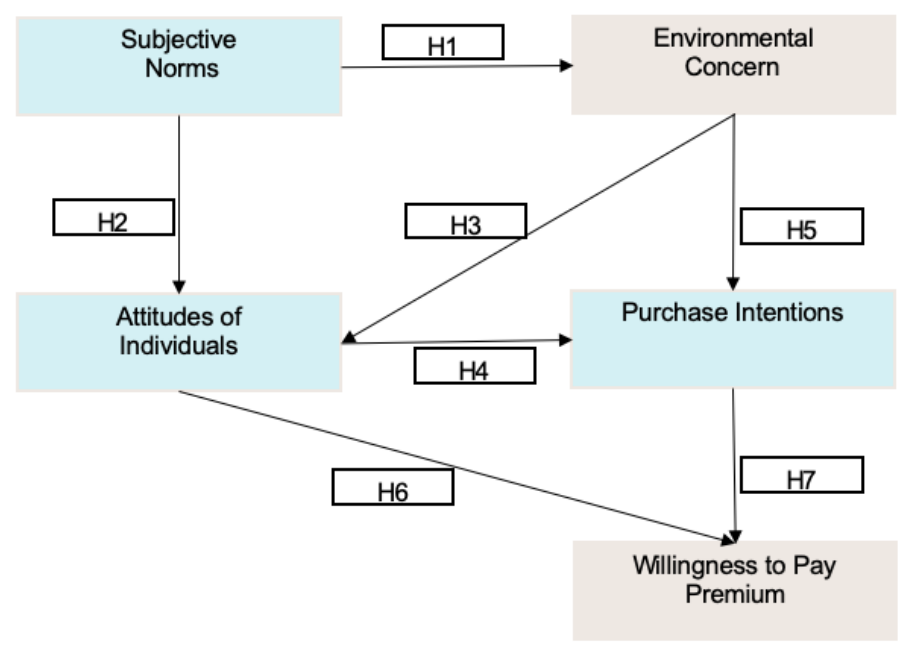

Figure 2. Author's Contribution based on the Hypothesis

\section{Research Methodology \\ 3.1 Sample profile}

The research has been carried out in the Indian as the objective was to and intends to examine the behavior of millennial customers towards green cosmetic products. India is the second-largest economy with the population being only second to China. Millennials occupy a considerable proportion of the total population accounting for $34 \%$. Consciousness among the millennials about the advantages of environmentally safe items is high. (Jaiswal \& Kant, 2018). Higher educational and awareness levels compared to the earlier generations is responsible for higher environmental consciousness among the millennials
ISSN (Print): 2204-0595

ISSN (Online): 2203-1731 
(Prak ash \& Pathak, 2017). The socially aware behavior by people around the globe has led to a shift in the mindset of businesses (Prothero, 1990) which have started to offer a range of healthy, organic, renewable, and non-toxic goods on the market today.

The cosmetic industry is one of the fastest rising industries globally (Kumar S. , 2005) growing by more than $5.5 \%$ in 2018 with the Asia-Pacific cosmetic market makes up $41 \%$ of the revenue of the industry (Statista, 2020). Along with the high revenues and glam of the cosmetic industry, it has its disadvantages. The cosmetics industry produces plastic waste along with several toxic materials like water pollution and anionic surfactants (Friha, Karray, Feki, Jlaiel, \& Sayadi, 2014). This makes it important to study the behavior of millennial consumers in the cosmetic industry (Junaid \& Nasreen, 2012).

The questionnaire was be administered by conducting an anonymous survey online. To maintain a homogenous sample, the survey was circulated among 250 millennials from different cultures, academic backgrounds, and income levels. The questionnaire consisted of two sections: section one was based on the demographic outline of the respondents comprising of age, gender, etc. of the sample population. The second part consisted of Likert scale statements intended to measure the variables of the model as suggested in figure 2 .
The sample size to variable ratio was decided based on the guidelines according to Osborne \& Costello (2004). Even though some literature suggests a minimum of 5 to 1 ratio between sample size and variables, this study has used roughly a ratio of 10 to 1 to ascertain that the scale used in this study is sufficient. The number of variables used in this analysis was 26 and the sample size was 251 .

\begin{tabular}{ll}
\hline & N \\
\hline Gender & \\
Male & 123 \\
Female & 128 \\
\hline Qualification & \\
Undergraduate & 107 \\
Post Graduate & 132 \\
Doctorate & 12 \\
\hline Employment & \\
Student & 121 \\
Employed & 113 \\
Home-maker & 17 \\
\hline
\end{tabular}

Table 1. Demographic Profile: Authors Calculation

\begin{tabular}{lll}
\hline & $\mathrm{N}$ & $\%$ \\
\hline Gender & 123 & $49 \%$ \\
Male & 128 & $51 \%$ \\
Female & & \\
\hline Qualification & 107 & $43 \%$ \\
Undergraduate & 132 & $52 \%$ \\
Post Graduate & 12 & $5 \%$ \\
Doctorate & & \\
\hline Employment & 121 & $48 \%$ \\
Student & 113 & $45 \%$ \\
Employed & 17 & $7 \%$ \\
Home-maker & & \\
\hline
\end{tabular}

Table 1. Demographic Profile: Authors Calculation

\subsection{Analysis of Strategy}

The model was analyzed using AMOS SPSS software. Confirmatory Factor Analysis (CFA) was overseen to determine the associations amongst the latent variables EC (environmental Concern), SN (Subjective Norms), AI (Attitude of Individuals), PI (Purchase Intention), and WTP (Willingness to Pay). The aim is to evaluate the performance of the experiment by considering the goodness of fit and evaluating the theory by testing the hypothesis between the exogeneous (predictor variables) and endogenous dependent variables.

A Likert Scale was introduced to gather the responses varying from 1 - Strong Agreement to 5 - Strong Disagreement. The same has been used to perform the analysis of purchase behavior as studied by Kant \& Jaiswal,2018 and Kumar et. al, 2017.

\section{$4 \quad$ Analysis}

SEM was adopted to validate the conceptual structure and model hypothesis using AMOS-SPSS (Byrne,2001) with 
$\operatorname{maxi}$ mum likelihood estimation. This model is based on an approach consisting of two steps which include the measurement model and the structural equation model (Anderson and Ginberg, 1988).

\subsection{The Measurement Model}

We conduct CFA to assess the validity and reliability of the building components in the hypothesis. Before implementing the measurement model, the results were tested for outliers and the normality of the results was verified to satisfy the notion of the general linear model. No outliers were observed in the final sample and the variance from normality was insignificant. The kurtosis value was below the recommended value of \pm 3 and \pm 10 , the appropriate normality mark as per Kline,2011.

The measurement model indices do not completely satisfy the requirements as indicated by the recommended values although they fulfill the suggested values as indicated by Baumgartner et.al. 1996, and Doll, Xia, and Torkzadeh, 1994), who suggested that the CFI, TLI, and GFI values are acceptable if they are $>=0.8$. Additionally, the CFI value being closer to 0.9 relatively shows a good fit with the proposed model depicting CFI $=0.893$ (Bentler P. M. 1990). The chi-square and RMSEA were 0.0989 and 0.08 respectively with $\mathrm{p}>0.05$ as per the recommended values (Wheaton et al. 1977). The RMSEA $<=0.08$ indicates sufficient goodness of fit of the measurement model as recommended by MacCallum \& Browne, 1996; Bryne, 2013. The CFI and TLI are more than 0.8 indicating the goodness of fit of the measurement model (Xia \& Yang, 2019). The GFI value is between $0-1$, closer to 1 indicating a good fit (Kingdom \& Prins. 2016). The SRMR value which is closer to zero indicates a good fit as per the study by $\mathrm{Hu} \&$ Bentler, 1999.

\begin{tabular}{llllll}
\hline RMSEA & $\begin{array}{l}\text { Chi } \\
\text { Square } \\
((\mathrm{X} 2) / \mathrm{df})\end{array}$ & CFI & TLI & SRMR & GFI \\
& & & & \\
\hline 0.08 & 0.099 & 0.893 & 0.874 & 0.217 & 0.8504 \\
\hline
\end{tabular}

Table 2. Goodness of Fit Statistics: Authors Calculation

Cronbach's $\alpha$ test was administered to investigate construct reliability. The values of Cronbach's $\alpha$ of the model are as per the threshold value of 0.7 (Nunnally, 1978). The AVE (Average Variance Extracted) and CR (Composite Reliability) were used to view the convergent validity of the model. Standardized loadings of the factors of all constructs fall within the level of 0.6 (Chin et at, 1997). The CR of the factors exceeds the cut-off value of 0.6 as suggested by Bagozzi and Yi,1988. The AVE of the constructs also follows the 0.5 critetion as indicated by Fornell and Larcker,1981. The comprehensive outline of the same is shown in Table 3. 


\begin{tabular}{lllllll}
\hline Item & & Variable & $\begin{array}{l}\text { Factor } \\
\text { Loading }\end{array}$ & CR & AVE & $\begin{array}{c}\text { Cror } \\
\text { Alph }\end{array}$ \\
\hline EC1 & $\leftarrow$ & EC & 1 & & & \\
EC2 & $\leftarrow$ & EC & 1.024 & & & \\
EC3 & $\leftarrow$ & EC & 0.937 & & & \\
EC4 & $\leftarrow$ & EC & 1.171 & & & \\
EC5 & $\leftarrow$ & EC & 0.985 & 1.01 & 1.0536 & 0.822 \\
\hline PSN1 & $\leftarrow$ & PSN & 1 & & & \\
PSN3 & $\leftarrow$ & PSN & 1.011 & & & \\
PSN4 & $\leftarrow$ & PSN & 1.102 & & & \\
PSN5 & $\leftarrow$ & PSN & 0.88 & 1.0007 & 1.0027 & 0.787 \\
\hline AI1 & $\leftarrow$ & PSN & 1.05 & & & \\
AI2 & $\leftarrow$ & PSN & 1 & & & \\
AI3 & $\leftarrow$ & PSN & 1.135 & & & \\
AI4 & $\leftarrow$ & PSN & 1.028 & & & \\
AI5 & $\leftarrow$ & PSN & 1.089 & & & \\
A16 & $\leftarrow$ & PSN & 1.085 & 1.0203 & 1.1351 & 1.083 \\
\hline PI1 & $\leftarrow$ & PI & 1 & & & \\
PI3 & $\leftarrow$ & PI & 0.702 & 0.851 & 0.7464 & 0.739 \\
\hline WTP2 & $\leftarrow$ & WTP & 1 & & & \\
WTP5 & $\leftarrow$ & WTP & 1.116 & 1.0580 & 1.1227 & 0.846 \\
\hline
\end{tabular}

Table 3. Measurement of reliability and validity: Authors Calculation

The square root of AVE of the constructs was paralleled with the correlation of each of the constructs to ensure the data satisfies the condition of discriminant validity. Table 4 indicates that the square root of AVE is higher than the correlation values, thereby confirming discriminant validity.

\begin{tabular}{llllll}
\hline & PSN & EC & AI & PI & WTP \\
\hline PSN & $\mathbf{1 . 0 2 6 4}$ & & & & \\
\hline EC & 0.7846 & $\mathbf{1 . 0 0 1 4}$ & & & \\
\hline AI & 0.5210 & 0.5120 & $\mathbf{1 . 0 6 5 4}$ & & \\
\hline PI & 0.8609 & 0.6317 & 0.6738 & $\mathbf{0 . 8 6 3 9}$ & \\
\hline WTP & 0.6227 & 0.6272 & 0.4872 & 0.7547 & $\mathbf{1 . 0 5 9 6}$ \\
\hline
\end{tabular}

Table 4. Measurement of reliability and validity: Authors Calculation

\subsection{Structural Model}

The Chi-Square $((\chi 2) / \mathrm{df})=0.099$ which is the goodness of fit statistic, $\quad \mathrm{CFI}=0.893, \quad \mathrm{RMSEA}=0.082, \quad \mathrm{TLI}=0.874$, and $\mathrm{SRMR}=0.217$ ) fit the results of the data fairly as insinuated by
Hair et al, 2015. The proposed model was further examined using path analysis by utilizing standardized regression weights and significant values. This was used to estimate the explanatory power of independent variables in explaining the dependent variables. The analysis is contained in Table 5 . 


\begin{tabular}{llll}
\hline Hypothesis & Path & Estimate & p-value \\
\hline H1 & SN $\rightarrow E C$ & 0.4239 & $* * *$ \\
H2 & SN $\rightarrow A I$ & 0.2666 & 0.034 \\
H3 & EC $\rightarrow A I$ & 0.2245 & 0.2245 \\
H4 & $\mathrm{AI} \rightarrow P I$ & 0.1673 & $* * *$ \\
H5 & EC $\rightarrow P I$ & -0.4137 & $* * *$ \\
H6 & AI $\rightarrow W T P$ & 0.0915 & $* * *$ \\
H7 & PI $\rightarrow W T P$ & 0.3371 & $* * *$ \\
\hline
\end{tabular}

Table 5. Standardised regression weights and P Values: Authors Calculation ${ }^{*}$ Significant p-value at 0.05 level, ${ }^{* *}$ Significant p-value at 0.01 level

\subsection{The Findings}

The hypothesized model of the current research looked at the direct and/or indirect impact of Personal and Subjective Norms (SN), environmental concern (EC), Attitudes of Individuals (AI), Purchase Intention (PI) on Willingness to Pay Premium (WTP) for green cosmetics. The analysis suggests that attitudes of individuals (AI) acts as both an endogenous (dependant) and exogeneous (independent) variable in impacting the willingness to pay a premium for green cosmetics in India.

The findings related to the demographic profile suggest that both male and female millennial respondents have a positive outlook towards green cosmetics. However, men are more $12 \%$ more likely than women to pay a premium for green cosmetics in India. Education has an integral role in the proenvironmental behavior of people. Individuals with higher qualifications show more intention to purchase green cosmetics, probably due to more information and awareness. The employment data shows that the individuals in the workforce are $48.2 \%$ more likely to purchase green commodities than home-makers and students. This may be because they get more exposure to such commodities and have more purchasing power than the others.

The conclusions drawn from the path analysis are displayed in Table 5 indicate that seven hypotheses were accepted between 0.001 and 0.05 . The study confirms that the attitude of individuals is an important factor that influences willingness to pay a premium and purchase intention. Subjective norms also play a relatively important role in influencing environmental concerns and individual attitudes. The proposed model as indicated in figure 3 of the paper.

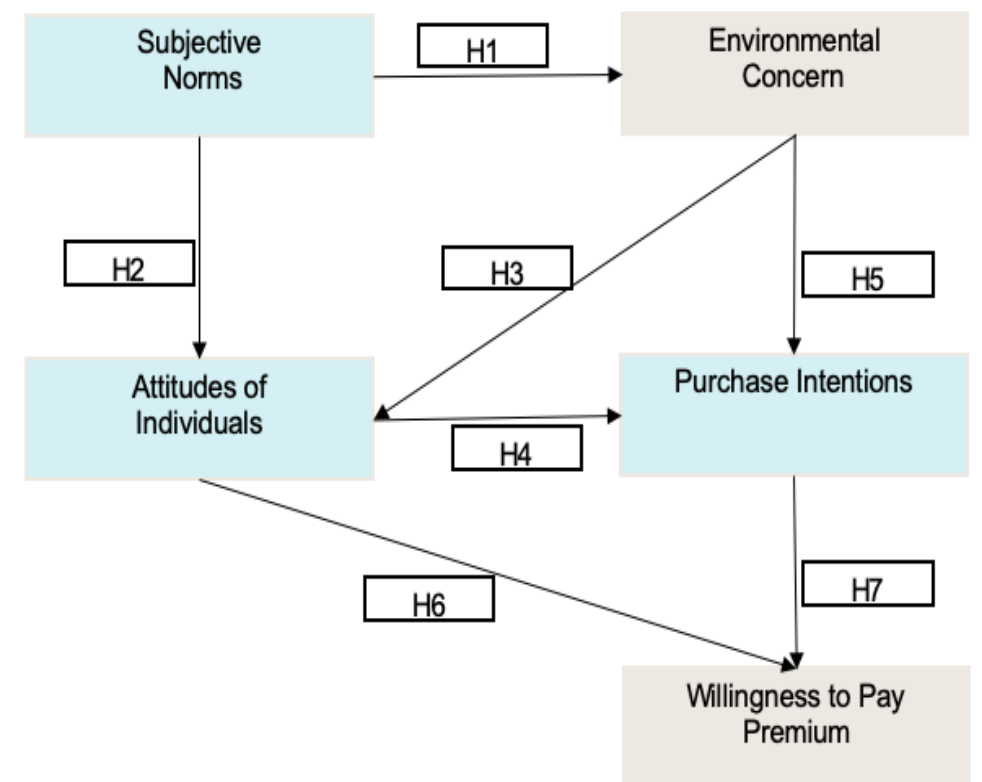

Figure 3: Model proposed by Author 
intent Organizations should be conscious that the consumption ethics ions and willingness to pay premium among Indian millennials towards green cosmetics based on the relationships between factors viz. subjective norms (SN), environmental concern (EC), attitudes of individuals (AI) with green purchase intention (PI) and willingness to a paid premium (WTP) indirectly and directly. While much work has been done on the factors impacting purchase intention (Huque et. al. 2014; Lai and Cheng, 2016; Jaiswal and Kant, 2018), no related studies have been found which evaluate the three cognitive factors (EC, SN, AI) antecedents of green purchase intention and willingness to pay a premium directly or indirectly in the Indian context. The empirical paper recognized that attitudes of millennials towards green cosmetics impact the willingness to pay a premium for these commodities explicitly and implicitly via purchase intentions. The intention of this study is, therefore, to resolve this untested relationship through the use of a structural equation model in the Indian cosmetic industry.

The outcome of analysis validated all seven hypothesized relationships and found that they were in line with the conceptual background in both a global and Indian environment and is shown to be coherent with findings of Lai and Mostafa, 2007; Kumar, Manrai \& Manrai, 2017; Yadav \& Pathak, 2016.

Green consumerism in India is still at its beginning phase and the mindfulness and accessibility of such items are lower contrasted with the Western markets (Mostafa,2007). Awareness should be expanded among the individuals by 'environmental education' and green affirmation projects to make individuals educated about and persuade them to purchase earth safe items (Lai and Cheng, 2016).

The role of attitudes of individuals in influencing green purchase behavior is in line with that of Chan,2001; Jaiswal and Kant,2018. However, no prior research has evaluated factors such as environmental concern and personal and social norms on the green purchase attitude.

The proposed model is harmony with the Theory of Planned Behaviour and adds to the model by stating that millennials in India are willing to spend more for green and natural cosmetic items, subject to personal and social norms, environmental concerns, attitudes of the individual, and purchase intention.

\subsection{Managerial and public policy implications-}

The study also offers some valuable insights for manufacturers, retailers, and marketers to investigate the potential of environment-friendly beauty products. Since subjective norms indirectly (via environmental concern and attitudes of individuals) affects purchase intentions and the attitudes of individuals directly and indirectly (via purchase intentions) affects willingness to pay, marketers need to study the subjective norms and attitude formations for the products more critically.

they promote in their marketing messages act as a key driver in influencing the environmental decisions of their buyers(Peattie \& Peattie, 2009). Buyers vary in the logical and emotional determinants of their preference for green consumption they derive advertising messages depending on how well informed they are (Kim, Yun, Lee, \& Ko, 2015). Therefore marketers need to direct different types of messages for each category of buyers and potential buyers. It is necessary marketers to come up with communication efforts aimed at making the consumers more aware and increasing their knowledge about organic and green cosmetic products and their efforts to reduce pollution and promote eco-friendly behavior (Kumar, Manrai \& Manrai, 2017). The marketing landscape is constantly evolving because of the change in attitudes of individuals towards pro-environmental behavior (Kotler, 2011). As consumers become more and more aware of the carbon emissions and climate change issues, there may be more shift towards environmentally friendly products in India (Diallo, 2012).

A tenable organization orientation has pros such as finding new goods and opportunities, exploiting new technologies, stimulating innovation, increasing productivity, and inspiring and retaining employees (Hopkins et al. 2009). Several multinational fairly cosmetic corporations have already actually switched to a greener cosmetic product which for the most part is organic and particularly has a much lesser carbon footprint, however, not many Indian millennial consumers are aware of such products. It is highly integral for marketers to develop authentic advertisements to make consumers aware of their products and their value benefits in terms of quality and sustainability (Antonetti and Maklan, 2014).

The paper can support marketers in understanding and adjust elements of their marketing mix to come up with strategies to influence the behaviors of their customers in India. In a collectivist society like India, it is highly vital to aid the role of subjective norms and their impact on the attitudes of consumers and their purchase intention. Along with this, the perceived environmental concern of individuals is also vital and marketers should aim at creating a brand message which impacts the individual and society as a whole. The study also provides insights into the willingness to pay for millennials in India. The research concludes that, with the correct consumer attitude w.r.t green cosmetics and knowledge of the product availability and its benefits, they are willing to pay a premium across green cosmetics.

To change individual behavior towards green commodities, organizations need to subtly force individuals to change their habits. Many habits are part of the daily routines of human beings. The key to promoting the ecological behavior of individuals is by breaking their bad habits and promoting new ones. Habits are derived from cues that individuals get from the things going on around them. Companies may use features to get rid of bad 
patter

ns and promote positive ones.

The current research can also be used to offer insights from the public policy perspective. It states that it is important that environmental policymakers have an in-depth knowledge of modern consumer behavior and their attitudes towards green consumer products so that they can create awareness and educate people about the availability of such products. The environmental policies should be directed at increasing the environmental knowledge of the society to enhance green consumerism in India.

One of the most powerful ways to evoke eco-friendly behaviors is by utilizing the power of social influence. Studies, including this one, have found that there is a strong relationship between attitudes of buyers, concern for environmental welfare, and the social behavior of the buyers. Public policymakers should focus on spreading the environment supporting behavior in society as a whole to have an impact on the individual level. The focus should be laid on removing the negative tags of eco-friendly products which people view as lower in quality with less esthetic appeal and more costly. Instead, the focus should be laid on the benefits of using such products and they should be promoted as for their out of the box approaches, novelty, and sustainability outlooks.

\section{Limitations of the Study}

The results of the paper are in agreement with both, the theoretical background and the overall notion on the topic. Despite this, there are a few limitations to the study. Although the study offers a heterogeneous populace with individuals from varied academic backgrounds, professions, and gender; a few elements that contribute to the differences at a deeper level might have not been considered. The questionnaire provided to the participants was self-administered and there may be a gap in the way the respondents answer the questions and how they behave. There is no evidence of the expressed behavior translating into actual behavior This problem is an issue to many researchers such as Kumar, Manrai \& Manrai, 2017; Jaiswal and Kant, 2018. These factors can be studied further by future research scholars. Factors such as involvement, trust, and value can also be studied and added to the framework of the current study.

\section{References}

[1]. Ajzen, I. (1991). The Theory of Planned Behavior. Organizational Behavior and Human Decision Process, 179-221.

[2]. Ajzen, I. (2011). The theory of planned behaviour: Reactions and reflections. 1113-1127.

[3]. Al-Swidi, A., Huque, S. M., Hafeez, M. H., \& Shariff, M. N. (2014). The role of subjective norms in theory of planned behavior in the context of organic food consumption. British Food Journal.
[4]. Allport, G. W. (1935). Attitudes: a handbook of social psychology. Clark University Press, Worceste.

[5]. Anderson, J. C., \& Gerbing, D. W. (1988). Structural equation modeling in practice: A review and recommended two-step approach. Psychological bulletin, 103(3), 411.

[6]. Bamberg, S., Ajzen, \& Schmidt. (2003). Choice of travel mode in the theory of planned behavior: The roles of past behavior, habit, and reasoned action. Basic and applied social psychology, 175-187.

[7]. Banerjee, S. (2017). "Corporate environmentalism and the greening of strategic marketing: implications for marketing theory and practice". Charter, M. (Ed.), Greener Marketing: A Responsible Approach to Business, Routledge, Abingdon, 16-40.

[8]. Barber, N., \& C Taylor, S. S. (2009). Wine consumers' environmental knowledge and attitudes: influence on willingness to purchase. International Journal of Wine Research, 59-72.

[9]. Basu, S., Thomas, J., \& Acharya, S. (2007). Prospects for growth in global nutraceutical and functional food markets: a Canadian perspective. Australian Journal of Basic and Applied Sciences, Vol. 1 No. 4, 637-649.

[10]. Baumgartner, H., \& Homburg, C. (1996). Applications of structural equation modeling in marketing and consumer research: A review. International journal of Research in Marketing, 13(2), 139-161.

[11]. Bentler, P. M. (1990). Comparative fit indexes in structural models. Psychological bulletin, 107(2), 238.

[12]. Brown, J. D., \& Wahlers, R. G. (1998). The Environmentally Concerned Consumer: An Exploratory Study. Journal of Marketing Theory and Practice, 39-47.

[13]. Byrne, B. M. (2013). Structural equation modeling with Mplus: Basic concepts, applications, and programming. Routledge.

[14]. Chan, R. Y. (2001). Determinants of Chinese consumers' green purchase behavior. Psychology and Marketing, 389-413.

[15]. Chang, M. (1998). Predicting unethical behavior: a comparison of the theory of reasoned action of the theory of planned behavior. Journal of Business Ethics, Vol. 17 No. 16, 1825-33.

[16]. Charter, M., Peattie, K., Ottman, J., \& Polonsky, M. J. (2002). Marketing and sustainability. Centre for Business Relationships, Accountability, Sustainability and Society. The Centre for Sustainable Design. 
[17]. C [29]. Gilbert, D. T., \& Malone, P. S. (1995). The

haudhary, R., \& Bisai, S. (2018). Factors influencing green purchase behavior of millennials in India. Management of Environmental Quality Volume 29 Issue 5 .

[18]. Chekima, B., Wafa, S. A., Igau, O. A., Chekima, S., Laison, S., \& Jr., S. (2015). Examining green consumerism motivational drivers: does premium price and demographics matter to green purchasing? Journal of Cleaner Production, 3436-3450.

[19]. Chen, T., \& Chai, L. (2010). Attitude towards the environment and green products: consumers' perspective. Manag. Sci. Eng., 4 (2), 27.

[20]. Constantinos, N. L., \& Dionysis, S. (2017). Gray Shades of Green: Causes and Consequences of Green Skepticism. Journal of Business Ethics volume 144, 401-415.

[21]. Diaz-Rainey, I., \& Ashton, J. K. (2011). Profiling potential green electricity tariff adopters: green consumerism as an environmental policy tool? Business Strategy and the Environment, 456-470.

[22]. Diekmann, A., \& Preisendörfer, P. (2003). Green and greenback: The behavioral effects of environmental attitudes in low-cost and high-cost situations. Rationality and Society, 441-472.

[23]. Doll, W. J., Xia, W., \& Torkzadeh, G. (1994). A confirmatory factor analysis of the end-user computing satisfaction instrument. MIS Quarterly, 18, 453-461. http://doi.org/ckdmrk

[24]. Dunlap, R. E., \& Van Liere, K. D. (1978). The "new environmental paradigm". The journal of environmental education, 10-19.

[25]. Ellen, P. S., Wienner, J. L., \& Walgren, C. C. (1991). The Role of Percieved Consumer Effectiveness in Motivating Environmentally Conscious Behaviors. Journal of Public Policy and Marketing.

[26]. Farzana, Q., Azila, J., \& Mohammad, J. (2020). Does It Matter Who Exhibits More Green Purchase Behavior of Cosmetic Products in Asian Culture? A Multi-Group Analysis Approach. International Journal of Environmental Responsibility and Public Health.

[27]. Friha, I., Karray, F., Feki, F., Jlaiel, L., \& Sayadi, S. (2014). Treatment of cosmetic industry wastewater by submerged membrane bioreactor with consideration of microbial community dynamics. International Biodeterioration \& Biodegradation, 88, 125-133.

[28]. Gadenne, D., Sharma, B., Kerr, D., \& Smith, T. (2011). The influence of consumers' environmental beliefs and attitudes on energy saving behaviours. Energy policy, 39(12), 7684-7694. correspondence bias. Psychological Bulletin, 117(1), 21-38.

[30]. Glegg, G., Richards, J., Heard, J., \& Dawson, J. (2005). Barriers to Green Buying: Household Chemicals. A Report for the Clean Water Initiative. Marine and Coastal Policy Research Group, United Kingdom: University of Plymouth.

[31]. Gleim, M. R., Smith, J. S., Andrews, D., \& Cronin, J. J. (2012). Against the Green: A Multi-method Examination of the Barriers to Green Consumption. Journal of Retailing.

[32]. Gohil, A. S. (2020). An Empirical Study on Profitability Analysis of Selected Fmcg Companies in India. UGC CARE Journal, 147-153.

[33]. Gorodnichenko, Y., \& Roland, G. (2012). Understanding the individualism-collectivism cleavage and its effects: Lessons from cultural psychology. nstitutions and comparative economic development, 213-236.

[34]. Hair, J. F., Black, W. C., Babin, B. J., Anderson, R. E., \& Tatham, R. L. (1998). Multivariate data analysis. , Babin, B. J., Anderson, R. E., \& Tatham, R. L. (1998). Multivariate data analysis (Vol. 5, No. 3), 207-219.

[35]. Ham, M., Jeger, M., \& Ivković, A. F. (2015). The role of subjective norms in forming the intention to purchase green food. Economic Research- Taylor \& Francis, Volume 28.

[36]. Hartmann, P., \& Apaolaza-Ibáñez, V. (2012). Consumer attitude and purchase intention toward green energy brands: The roles of psychological benefits and environmental concern. Journal of business Research, 65(9), 1254-1263.

[37]. Hu, L. T., \& Bentler, P. M. (1999). Cutoff criteria for fit indexes in covariance structure analysis: Conventional criteria versus new alternatives. Structural equation modeling: a multidisciplinary journal, 6(1), 1-55.

[38]. Iris, V., \& Wim, V. (2008). Sustainable food consumption among young adults in Belgium: Theory of planned behaviour and the role of confidence and values. Ecological Economics Volume 64, Issue 3, 542-553.

[39]. Jaiswal, D., \& Kant, R. (2018). Green purchasing behavior: A conceptual framework and empirical investigation of Indian consumers. Journal of Retailing and Consumer Service, 60-69.

[40]. Jang, Y. K., \& Bonn, M. (2011). Generation Y consumers' selection attributes and behavioral intentions concerning green restaurants. International Journal of Hospitality Management, Vol. 30 No. 4, 803-811. 
[41]. J

oshi, Y., \& Rahman, Z. (2015). Factors Affecting Green Purchase Behaviour and Future Research Directions. INTERNATIONAL STRATEGIC MANAGEMENT REVIEW , 128-143.

[42]. Junaid, A. B., \& Nasreen, R. (2012). Determination of Consumer Behaviour amongst Millennials in Dermaceuticals (Skin Care Products). International Journal of Marketing Studies 4.3, 88.

[43]. Kaiser, F., Wölfing, S., \& Fuhrer, U. (1999). Environmental attitude and ecological behaviour. Journal of Environmental Psychology, 1-19.

[44]. Kaur, J., Duggal, V., \& Suri, S. (2019). To study the Factors effecting Purchase of Green products and their relation to the Purchase decision of Green products for Generation $\mathrm{Z}$ in India. Journal of Asia Entrepreneurship And Sustainability, 21-63.

[45]. Kingdom, A. A., \& Prins, N. (2016). Psychometric Functions. Psychophysics (Second Edition), 55-117

[46]. Khare, A. (2015). "Antecedents to green buying behaviour: a study on consumers in an emerging economy. Marketing Intelligence \& Planning.

[47]. Kumar, B., Manrai, A. K., \& Manrai, L. A. (2017). Purchasing behaviour for environmentally sustainable products: A conceptual framework and empirical study. Journal of Retailing and Consumer Services, 1-9.

[48]. Kumar, S. (2005). Exploratory analysis of global cosmetic industry: major players, technology and market trends. Technovation 25.11, 1263-1272.

[49]. Lai, C., \& Cheng, E. W. (2016). Green Purchase Behaviour of Undergraduate Students in Hong Kong. The Social Science Journal, 67-76.

[50]. Lee, P., Lusk, K., Mirosa, M., \& Oey, I. (2014). The role of personal values in Chinese consumers' food consumption decisions: a case study of healthy drinks. Appetite, Vol. 73, 95-104.

[51]. López-Fernández, A. M. (2020). Price sensitivity versus ethical consumption: a study of Millennial utilitarian consumer behavior. Journal of Marketing Analytics volume 8, 57-68.

[52]. MacCallum, R. C., Browne, M. W., \& Sugawara, H. M. (1996). Power analysis and determination of sample size for covariance structure modeling. Psychological methods, 1(2), 130.

[53]. Majláth, M. (2010). Can individuals do anything for the environment? The role of perceived consumer effectiveness. Proceedings of FIKUSZ, 157-166.

[54]. Montaño, D. E. (2015). Theory of reasoned action, theory of planned behavior, and the integrated behavioral model. Health behavior: Theory, research and practice 70.4, 231.

[55]. Moser, A. K. (2016). Consumers' purchasing decisions regarding environmentally friendly products: An empirical analysis of German consumers. Journal of Retailing and Consumer Services , 389-397.

[56]. Ottoman, J. (1998). Green Marketing: Opportunity for Innovation. The Journal of Sustainable Product Design 60, 136-667.

[57].

[58]. Paettie, K. (2001). Towards Sustainability: The Third Age of Green Marketing. The Marketing Review, 129-146.

[59]. Pelling, E. L., \& White, K. M. (2009). The Theory of Planned Behavior Applied to Young People's Use of Social Networking Web Sites. Cyber Psychology \& Behavior, 755-759.

[60]. Pickett-Baker, J., \& \& Ozaki, R. (2008) Pro-environmental products: marketing influence on consumer purchase decision. Journal of consumer marketing.

[61]. Prakash, G., \& Pathak, P. (2017). Intention to buy eco-friendly packaged products among young consumers of India: A study on developing nation. Journal of Cleaner Production, 385-395.

[62]. Prothero, A. (1990). Green consumerism and the societal marketing concept: marketing strategies. Journal of Marketing Management, 87-103.

[63]. Smith, A., Stirling, A., \& Berkhout, F. (2005). The governance of sustainable socio-technical transitions. Research Policy 34, 1491-1510.

[64]. Song, M., Cen, L., Zheng, Z., Fisher, R., Liang, X., Wang, Y., \& \& Huisingh, D. (2017). How would big data support societal development and environmental sustainability? Insights and practices. Journal of Cleaner Production, 489-500.

[65]. Soyez, K. (2012). How national cultural values affect pro-environmental consumer behavior. International Marketing Review.

[66]. Sparks, P., \& Shepherd, R. (1992). Self-Identity and the Theory of Planned Behavior: Assesing the Role of Identification with "Green Consumerism". Social Psychology Quarterly, 388-399.

[67]. Statista. (2020). Retrieved from https://www.statista.com/statistics/243959/breakdo wn-of-the-cosmetic-market-worldwide-bygeographic-zone/

[68]. Statista (2020) Retrieved from https://www.statista.com/outlook/70010000/119/cos metics/india\#market-globalRevenue

[69]. Stern, P. (2000). Toward a coherent theory of environmentally significant behavior. Journal of Social Issues, 407-424.

[70]. Thøgersen, J. (2009). onsumer decision-making with regard to organic food products. Traditional food production and rural sustainable development: A

ISSN (Print): 2204-0595 ISSN (Online): 2203-1731 
uropean challenge. Journal of Psychology and Marketing, 173-192.

[71]. Verma, J., \& Triandis, H. C. (1999). The measurement of collectivism in India. Fourteenth International Congress of the International Association for Cross-Cultural Psychology, 256265.

[72]. Wei, S., Ang, T., \& Jancenelle, V. E. (2018). Willingness to pay more for green products: The interplay of consumer characteristics and customer participation. Journal of Retailing and Consumer Services, 45, 230-238.

[73]. Wheaton, B., Muthen, B., Alwin, D. F., \& Summers, G. F. (1977). Assessing reliability and stability in panel models. Sociological methodology, 8, 84-136.

[74]. Wheeler, L., Reis, H. T., \& Bond, M. H. (1989). Collectivism-individualism in everyday social life: The middle kingdom and the melting pot. ournal of Personality and Social Psychology, 79-86.

[75]. Xia, Y., Yang, Y. RMSEA, CFI, and TLI in structural equation modeling with ordered categorical data: The story they tell depends on the estimation methods. Behav Res 51, 409-428 (2019)

[76].

[77]. Xu, P., Zeng, Y., Fong, Q., Lone, T., \& Liu, Y. (2012). Chinese consumers' willingness to pay for green- and eco-labeled seafood. Food Control Volume 28, Issue 1, 74-82.

[78]. Yadav, R., \& Pathak, G. S. (2016). Young consumers' intention towards buying green products in a developing nation: Extending the theory of planned behavior. Journal of Cleaner Production, 732-739.

[79]. Zhang, B., Fu, Z., Huang, J., Wang, J., Xu, S., \& Zhang, L. (2018). Consumers' perceptions, purchase intention, and willingness to pay a premium price for safe vegetables: A case study of Beijing, China. Journal of Cleaner Production Volume 197, Part 1, 1498-1507. 